\title{
There's No Such Thing as Free Lunch but Envy among Young Facebookers
}

\author{
Tassawar Iqbal ${ }^{1}$, Muhammad Tariq Yousafzai ${ }^{2}$, Sabeen $\mathrm{Ali}^{3}$, Kinza Sattar ${ }^{4}$, \\ Muhammad Qaiser Saleem ${ }^{5}$, Usman Habib $^{6, *}$ and Atta ur Rehman Khan ${ }^{7}$ \\ ${ }^{1}$ Department of Computer Science, COMSATS Institute of Information Technology, Wah Campus, Pakistan \\ [e-mail: tassawar@ciitwah.edu.pk] \\ ${ }^{2}$ FAST School of Management, National University of Computer and Emerging Sciences, Peshawar, Pakistan \\ [e-mail: tariq.yousafzai@nu.edu.pk] \\ ${ }^{3}$ Department of Computer Science, COMSATS Institute of Information Technology, Abbottabad, Pakistan \\ [e-mail: sabeenali05@gmail.com] \\ ${ }^{4}$ Department of Computer Science, University of Lahore, Islamabad, Pakistan \\ [e-mail: sattar.kinza@gmail.com] \\ ${ }^{5}$ College of Computer Science and Information Technology, Al Baha University, Al Baha, Saudi Arabia \\ [e-mail: muhammad.qaiser.saleem@gmail.com] \\ ${ }^{6}$ Department of Computer Science, National University of Computer and Emerging Sciences, Peshawar, Pakistan \\ [e-mail: usman.habib@nu.edu.pk] \\ ${ }^{7}$ Department of Computer Science, Air University, Islamabad, Pakistan \\ [e-mail: dr@attaurrehman.com] \\ *Corresponding author: Usman Habib
}

Received December 25, 2017; revised April 9, 2018; accepted April 29, 2018; published October 31, 2018

\begin{abstract}
Facebook has quickly infused across cultures worldwide to become a common household term for diverse spectra of netizens, especially youngsters. Inherently, interactive in nature, Facebook provides a common cyber enabled platform for online interactions with social friends, living across the world. However, despite its merits, users also experience certain disadvantages, which include but are not limited to rise in feelings of social comparison, decline in self-esteem, contentment and general subjective well-being. This work aims to determine the role of Facebook in spreading envy and identify factors that trigger such emotions. Due to abductive nature of the study, we used pilot interviews and consulted relevant literature to formulate hypotheses. Further, we used deductive approach and conducted a survey. The results showed that frequent use of Facebook, particularly passive following is main predictor of envy, and social interaction is the biggest cause for development of envious feelings in Facebook users. However, insignificant variation was found while investigating relationship between envy and factors, such as pretentiousness, time spent, accomplishment, everything in life, likes on posts, popularity across genders, marital status and genre.
\end{abstract}

Keywords: Facebooking, Self-Esteem, Pretentious, Narcissism, Life Satisfaction, Netizens, Stalking, Web 2.0, Reed's Law, Social Technographics 


\section{Introduction}

$\mathbf{F}_{\text {acebook is a well-known name in companies that provide online social media and social }}$ networking services. The term social media is defined as, "The democratization of information, transforming people from content readers to content publishers. It is the shift from a broadcast mechanism to a many-to-many model, rooted in conversations between authors, people and peers" [1]. In domains of social media the Groundswell trend has gradually become popular in which netizens interact with one another through web 2.0 enabled technologies, such as Facebook. Launched in 2004, Facebook overtook, Myspace as the world's most popular website during 2009 [2], in terms of users which has since experienced a whopping growth to reach more than one billion users [3]. The rise in Facebook's popularity can be seen from its entry as word of the year in 2007 to New Oxford American Lexicon. Later in 2009, a verb "Unfriend" which refers to removal of a friend from Facebook was also selected as word of the year by Oxford Dictionary [4].

Facebook has immense importance for businesses, politicians, students and general public alike, due to its reach and ostensibly free of cost usage. According to Reed's Law, social media platforms such as Facebook have the ability to reach people within groups [1]. This is perhaps, one of the reasons that Facebook is popular among masses especially the millennials with more than $50 \%$ of people aged 18-34 who check Facebook status when they wake up [5]. There is a positive relationship between frequency of Facebook use and student's life satisfaction, social trust, civic engagement and political participation [6]. Whilst, there are positive outcomes, some drawbacks of Facebooking include, suppressing outdoor games [7], negative effect on health [8], privacy violations [9] and suspicion in social relationships [10]. Furthermore, the growing interest in multimedia data supported by Facebook has made it one of the significant parts of human life [11-12].

According to a report, Facebook's Director research admitted on social media that Facebook can worsen our mental health by causing mood swings and jealousy [13]. Moroever, excessive presence on Facebook leads to narcissism and narcissistic behaviours [14]. Such behaviours on Facebook refers to exhibition of grandiosity [15], a persistent need for admiration [16] and other self-promoting behaviours [17], and self-presentation to establish an image of themselves to others [18]. In addition to these, Facebook is also notoriously known for spreading jealousy to the extent that it may even endanger marriages. Most notably, Facebook sucks up precious productive hours and instills emotions of jealously due to excessive obsession with information collection pertaining to others [19]. We can presume that unnecessary online presence of youth on Facebook makes them compare themselves with others which triggers envy.

Envy and jealousy are quite similar but different terminologies. Envy refers to a phenomena of desire to possess something which others have but one cannot have it, while jealousy refers to losing something to a contender [3]. Envy as a complex mixture of psychological states which includes inferiority, injustice and resentment [20]. These feelings are mostly linked with increased motivation to improve oneself. Conversely, it's hard to deny that people are more likely to develop ill feelings towards others. Hence, due to this later tendency, we can assume there is a relationship between envy and some of the other anti-social behaviors, such as getting angry when others do not like, share and comment on our posts [17]. Subconsciously, one would consider it as a dangerous and destructive emotion, because it can give birth to hostility, which ultimately leads to aggression, frustration, mental suffering, 
depression and even violence in youth [21]; and may adversely affect a person's well-being and life satisfaction [22].

Much of the research on foregoing discussion concerning how Facebook impacts our lives had been done in developed countries, such as Singapore, USA, Germany and China. However, prior researchers have paid scarce attention to behavioral outcome of using Facebook in developing countries. According to a recent report of Internet World Statistics Library, the number of Facebook users now exceeds 30 million in Pakistan [23]. This number alone is greater than combined population of Scandinavian countries. These statistics makes Pakistan an interesting market for investigation in reference to behavioral outcomes of Facebook's usage. Like other countries, an overwhelming majority of Facebook users in Pakistan fall in the age range of 18-24 years, followed by a second largest group from 25-35 years age bracket [24]. Considering the number of users, popularity and expected growth of Facebook users in Pakistan, it is intriguing to study how Facebook is affecting behaviors of young People in Pakistan. In addition, this undertaking will help unravel whether the results are in agreement with other studies conducted elsewhere.

Like any other study, there are associated limitations to this undertaking which pertains to difficulties in finding the right gender balance in terms of respondents across students and professional. Moreover, delimitations of the study pertains to narrow focus of hypothesis which confine our scope that otherwise could have been extended.

The paper is organized as follows: Section 2 deals with a detailed literature review highlighting the impact of social media, specifically of Facebook on the behavior and lifestyle of people. Research questions of this study are highlighted in Section 3. Methodology is discussed in section 4. Section 5 deals with results and detailed discussions, and Section 6 Concludes the paper and provided future research directions.

\section{Literature Review}

Singla and Richardson conducted a research using data mining technique to find correlation between social networks and personal behavior over World Wide Web [25]. Their research clearly indicates that users who possess mutual friends, but do not communicate directly share common interest patterns in web searchers. Their other findings reveal that people who sent brief messages were more close to one another and required little formality in communications. In addition to these, the research proclaims that heavy users of text messaging were more likely to be in communication with opposite gender. In [26], the researchers incorporate a largest data set of 30 billion conversations among 240 million users of Microsoft Messenger instant messaging service. Their findings were in agreement with preceding discussion in reference to cross gender communications with regards to duration and frequency as compared to conversation with users of similar gender. Moreover, another study investigated behavioral characteristics to discover Facebook activities [27]. Their research reveals two primary user groups whose goals were to self-promote (broadcast) and to maintain relationships (communicate). The former groups were found to aggrandize their social network behaviors with deceptive behavior and the later group used white lies to supported their group cohesion.

In [28], the authors discussed social technographic ladder developed by Forrester research which categories users of social network sites depending on their patterns of social media consumption. The corresponding categories of users and the nature of their activities are described in Fig. 1. 


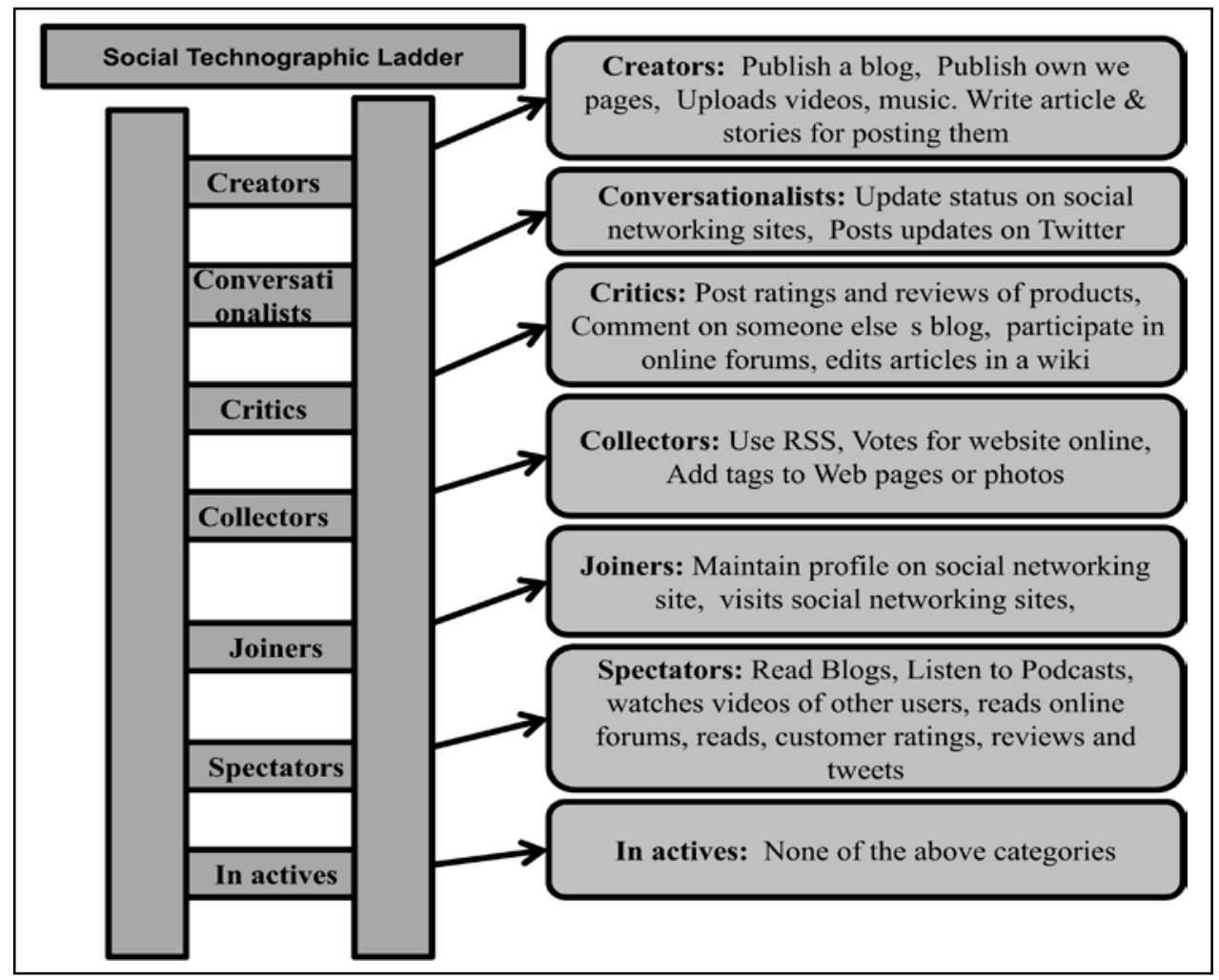

Fig. 1. The Social Technographic Ladder [28].

In [29], the authors examined experience of college students on Facebook. They investigated why and how college students use Facebook, type of interactions with others, and role of using Facebook in development of friendship. The research revealed that Facebook provides a very effective platform for people to express themselves. People with low self-esteem get more benefit from Facebook in terms of building social capital [30-31]. Facebook helps in maintaining relationships that would otherwise, be lost as people move away from each other. It helps in developing close and distant friendship and improves satisfaction level. It has been observed in [32], that people want to create a larger social media universe in terms of audience to enhance their satisfaction. Half of the users want a larger audience without being aware that they actually are visible to a much larger audience beyond their imagination.

In [19], the authors state that Facebook users only display positive aspects of their lives. Hence, there is a reciprocal inverse effect on cyber stalkers and they develop jealousy and even addiction [33]. Their research also unveils that there exists a positive correlation between time spent on Facebooking to jealousy and stalking on other users. It has been observed that most of the people share the best experiences and are at the best of their behaviour while posting on social networking sites. As a result, these practices may leave people depressed and affect their self-esteem, especially those who have tendency to compare. Research shows that women are more prone to Facebook addiction as compared to men [34]. Some people use Facebook to increase their self-esteem, while others use it to improve their personalities. It also induces narcissistic behaviour because of which most users post only positive things about themselves 
[35]. In [36], the aurthors found that active Facebook users believed in the statement "others had better lives than themselves". There seems to be consensus within literature that upward comparisons cause significant levels of envy on Facebook [3, 37].

It is pertinent to mention types of envy as we move ahead. Some levels of envy is inevitable because it is natural part of social interactions [38]. Benign envy leads to learning, motivation, better performance and achievement [39], however, malicious envy induces a desire to harm the envied objects which breeds hostility [38]. In [22], the authors investigate friends following and impact on users. Their findings were in accordance with social comparison theory which states that social information consumption may impact cognitive and affective well-being of users. Prolonged feelings of envy can adversely affect one's self-worth. As a result, dissatisfaction and withdrawal arises which leads to depression, reduced perceptions of one's well-being, and poor mental health [35, 37].

\section{Hypothesis}

Many recent research studies proclaim that consumption of information about others on social networking sites can cause envy on unprecedented scale [3, 19, 35, 40]. Moreover, this secretly held emotion of envy aggravates who use it frequently and those who have larger online social circle [6, 41, 42]. In particular, these envious feelings are developed in passive onlookers of the social networking sites who use to read only others posts [28]. Based on the findings of these studies, following hypotheses are formulated:

- H1: More envious feelings are developed in heavy users of Facebook than light users.

- H2: Facebook users with bigger circle of friends feel more envious than users with smaller circle of friends.

- H3: Passive following on Facebook is a reason for spreading envy.

Online persona of users is virtually always accessible for social comparison against person's real social identity and biographic information [43-44]. Most of the information presented by users is based on impression management and usually positively skewed [45-47]. Thus, the users who share fake positive achievements become popular in their online social universe may also cause envious feelings in others. Consequently, following hypotheses are formulated:

- H4: Posts related to someone's happy moments/success stories affect people negatively.

- H5: Someone’s popularity among friends circle may develop envious feelings in others.

Most of the previous studies focused on college populations and gender differences [48]. These studies rarely explored other dimensions, such as professionals, culture and marital status. According to [37], envy occurs in people of all genders, ages, and cultures. To further explore these dimensions, following hypotheses are formulated:

- H6: Females are affected more than males by Facebook in developing envy.

- H7: Professionals are more affected than students by Facebook in developing envy.

- H8: Unmarried people are more likely to develop envy through Facebook.

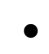




\section{Methodology}

The research onion proposed in [49] is used to locate the methodological underpinnings of this research (see Fig. 2). A positivist philosophical worldview has been espoused which values knowledge generated through use of senses as empirical evidence [49-51]. We used deductive research approach that suits better for quantitative studies. Considering the abductive nature of study, we initially used interview based technique along with literature to formulate hypotheses and then moved specifically to deductive approaches for use of surveys. The rest of discussion in methodology section pertains to conduct to pilot interviews, choice of research instruments and selection of participants for study. This will provide much needed justification for existence of research area [52].

\subsection{Survey}

Since this study explores relationships between Facebook use and envy, the survey method is used to collect data for testing the formulated hypotheses. Responses of survey were collected on 5-point Likert Scale with $1=$ strongly disagree to $5=$ strongly agree. To find correlation between concepts, Spearman's correlation method was used, keeping in view the non-parametric nature of data as recommended by [53-54]. The tests were performed using SPSS 20.

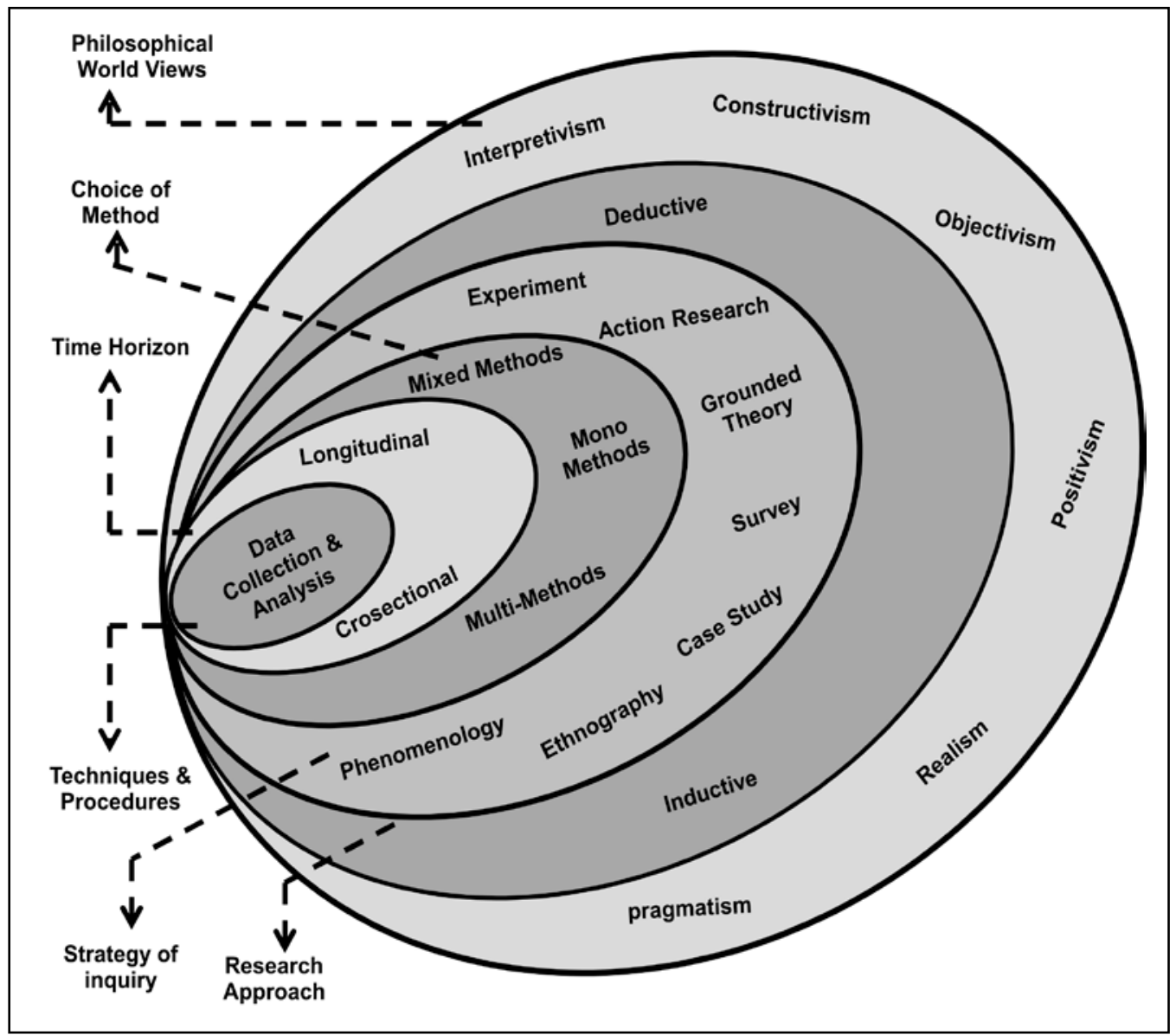

Fig. 2. The Research Onion [49] 


\subsection{Participants}

The participants are users of Facebook, which is the most widely used social networking site in Pakistan. In total, 204 volunteers participated in the survey. However, some of the participants felt hesitant in answering direct questions related to jealousy/envy and left the questionnaire half filled. Hence, 149 respondents completed the questionnaire comprising of 76 female and 73 male with ages ranging between 18 to 35 years. Among them, 74 respondents were married, whereas 75 respondents had single marital status. Moreover, 84 out 149 were students and the rest of the participants were professionals.

\subsection{Instrument}

The current study draws on questionnaire designed by [35, 55]. All items of the questionnaire were measured using a five-point Likert scale ranging from 1="strongly disagree" to $5=$ "strongly agree". The questionnaire includes demographic information to set apart the independent variables, such as gender, marital status, and trades. Other sections of the questionnaire were designed to find: i) frequency of Facebook usage, ii) feelings after using Facebook, iii) satisfaction level of users after using Facebook, and iv) factors that may induce envy among the users. To ensure internal consistency and reliability of research instrument, Cronbach's alpha was applied with resultant coefficient alpha value of 0.82 which indicates internal consistency [56].

\section{Results and discussion}

To find correlation between frequency of Facebook use and envy, Spearman's correlation was computed, and results reveal that $H 1$ is supported with $r s=0.270$ and $p$-value $<0.01$. Positive correlation was found between variables, which infer that heavy use of Facebook cause higher level of envy. $H 2$ hypothesized that big circle of Facebook friends is the reason behind envious feelings. However, the hypothesis is not supported by empirical evidence collected. The results indicate very weak positive correlation with $r s=0.056$. The results for $H 1$ and $H 2$ were in line with previous studies [3]. Assumptions made in $H 1$ and $H 2$ were of primary level to test relationships between frequency of Facebook use and larger friend's circle to envy. However, only usage frequency could determine the feeling of envy in users. Next assumption formulated in hypothesis $H 3$ was that passive following on Facebook is a reason for developing envy. To identify passive followers, a set of questions were asked to see if people are pretentious on Facebook. The results shows that there exists positive correlation between the variables with $r s=0.269$, and $p$-value $<0.05$. Consequently, passive users are soft target of developing envious feelings on Facebook. Likewise, the results are in line with previous studies [46], and shown in Table 1. Finding of [37] is also confirmed here that envy exists across all the cultures.

Table 1. Results of H1, H2, \& H3

\begin{tabular}{|c|c|}
\hline Variables & Envy \\
\hline \hline Time Spent & $0.270^{* *}$ \\
\hline Social Circle & 0.056 \\
\hline Being Pretentious & $0.269 * *$ \\
\hline$* *$ Correlation is significant at the 0.01 level (2-tailed) \\
\hline
\end{tabular}


Out of three initial level hypotheses, two were supported which laid the foundation to explore further assumptions formulated in hypothesis $\mathrm{H} 4$, and $\mathrm{H} 5$. Before testing these hypotheses, most common reasons of envy were determined through data. The results showed that social interaction is the biggest cause of envy, followed by Leisure/travel, success, and love, respectively. The calculated frequency responses of participants are given in Table 2 .

Table 2. Frequency Responses

\begin{tabular}{|c|c|c|}
\hline Variables & Frequency & Percentage \\
\hline \hline Travel/Leisure & 32 & 25.6 \\
\hline Social Interaction & 41 & 32.8 \\
\hline Success in general & 29 & 23.2 \\
\hline Love & 16 & 12.8 \\
\hline Money & 7 & 5.6 \\
\hline
\end{tabular}

To further study the preceding phenomenon in detail, we asked respondents if they feel $a$ sense of accomplishment after posting something positive about themselves. Results showed that $64 \%$ gave positive feedback, and this variable was correlated with envy to test the $H 4$. The correlation was positive with $r s=0.243$ and $p$-value $<0.01$. Hence, happy moments of someone's life are positively associated with envy. Table 3 shows the results of correlation.

Based on the reasons pertaining to envy described in Table 2, those users who shared positive moments of their life became popular among their social circle. Their popularity may also cause envious feelings in other for which we tested $\mathrm{H} 5$, and results indicates positive correlation between popularity and envy with $r s=0.241$, and $p$-value $<0.01$ as shown in Table 3.

Table 3. Summary of Correlation

\begin{tabular}{|c|c|}
\hline Variables & Envy \\
\hline \hline Posting positive things about oneself & $0.243^{* *}$ \\
\hline Popularity & $0.241^{* *}$ \\
\hline$* *$ Correlation is significant at the $\mathbf{0 . 0 1}$ level (2-tailed) \\
\hline
\end{tabular}

According to [37], envy occurs in people of all genders, ages, and cultures especially the younger ones. Moreover, it was found that feelings of being envious are developed more in female than male users. During pilot interviews, this response prompted us to formulate H6. It was tested against numerous variables which included, i) passive following on Facebook, ii) a sense of accomplishment after posting something positive about themselves, iii) popularity, iv) time spent on Facebook, v) everything in life, such as success, love and money, and vi) number of likes on posts. Result showed that $H 6$ is partially supported. The variables of passive following on Facebook and envy were positively correlated for females with $r s=0.322$ and $p$-value $<0.01$, however, in case of male users although correlation was positive but it was not significant. Likewise, similar relationship was found for popularity and envy. In case of females, positive correlation was found between envy and popularity with correlation coefficient $r s=0.329$ and $p$-value $<0.01$. In case of males, non-significant and weak positive correlation was found as shown in Table 4. The variables such as time spent on Facebook and accomplishment after posting positive posts were more positively correlated with envy in case of males compared to female users. For the rest of two variables "everything in life" and "likes on posts" were significantly positively correlated for both male and female users. 
Most of the previous studies were conducted to explore envious feeling in students. In this study, we also probed envious feelings in young professionals, which were ignored in the earlier studies. Thus, we formulated and tested hypothesis $H 7$ against the same six variables as given in Table 5.

Table 4. Envy -Male vs. Female

\begin{tabular}{|l|l|l|}
\hline \multirow{2}{*}{ Variables } & \multicolumn{2}{c|}{ Envy } \\
\cline { 2 - 3 } & Male (n=73) & Male (n=73) \\
\hline Pretentious & 0.201 & $0.322^{* *}$ \\
\hline Time Spent & $0.335^{* *}$ & 0.224 \\
\hline Accomplishment & $0.344^{* *}$ & 0.172 \\
\hline Everything in Life & $0.377^{* *}$ & $0.422^{* *}$ \\
\hline Likes on Posts & $0.395^{* *}$ & $0.306^{* *}$ \\
\hline Popular ${ }^{* *}$ Correlation is significant at the 0.01 level (2-tailed) \\
\hline \multicolumn{2}{|l}{} \\
\hline
\end{tabular}

A contrasting trend is exhibited in case of popularity and accomplishment on posts for students and professionals. Strong positive correlation was found between popularity and envy in case of students, whereas, strong positive correlation prevailed between accomplishment on posts and envy for professionals. The remaining variables had significant positive correlation with envy for both student and professional Facebookers.

Table 5. Envy - Student vs Professional

\begin{tabular}{|l|l|l|}
\hline \multicolumn{1}{|c|}{ Variables } & \multicolumn{2}{c|}{ Envy } \\
\hline & Student (n=84) & Professional (n=65) \\
\hline Pretentious & $0.240^{* *}$ & $0.281^{* *}$ \\
\hline Time Spent & $0.234^{* *}$ & $0.264^{* *}$ \\
\hline Accomplishment & 0.188 & $0.336^{* *}$ \\
\hline Everything in Life & $0.370^{* *}$ & $0.424^{* *}$ \\
\hline Likes on Posts & $0.328^{* *}$ & $0.393^{* *}$ \\
\hline Popular & $0.321^{* *}$ & 0.148 \\
\hline \multicolumn{3}{|c|}{ Correlation is significant at the 0.01 level (2-tailed) } \\
\hline
\end{tabular}

In order to test envy across marital status, hypothesis $\mathrm{H} 8$ was formulated and tested in the same manner. Respondent with single marital status appeared to be more envious in case of four variable (passive following, time spent, everything in life, and popularity) than married users. Married respondents appeared to be more envious for accomplishment on posts than single users. Detailed results are given in Table 6.

Table 6. Envy - Single vs Married

\begin{tabular}{|l|l|l|}
\hline \multicolumn{1}{|c|}{ Variables } & \multicolumn{2}{|c|}{ Envy } \\
\cline { 2 - 3 } & Single (n=75) & Married (n=74) \\
\hline Pretentious & $0.253^{* *}$ & 0.259 \\
\hline Time Spent & $0.253^{* *}$ & 0.220 \\
\hline Accomplishment & 0.131 & $0.499^{* *}$ \\
\hline Everything in Life & $0.452^{* *}$ & 0.263 \\
\hline Likes on Posts & $0.323^{* *}$ & $0.400^{* *}$ \\
\hline Popular & $0.279^{* *}$ & 0.194 \\
\hline \multicolumn{2}{|c|}{ Correlation is significant at the 0.01 level (2-tailed) } \\
\hline
\end{tabular}




\section{Conclusions and Future Work}

In this study, we investigated the relationship of Facebooking with envious feelings. It was found that passive following is attributed to development of envious feelings, and there is no relationship between envy and larger friends circle. Moreover, social interaction is biggest cause of envy, followed by travel, success, and love, respectively. Inconclusive results were found for variables across genders, which include pretentiousness, time spent on Facebook, accomplishments, things in life, likes on posts and popularity. Students and professionals exhibit similar envious feelings in terms of the highlighted variables. The students are more prone to develop envious feeling compared to professionals, whereas professionals are more vulnerable to envy in reference to popularity. Married respondents appeared more envious for accomplishment on posts, whereas users with single marital status experience higher levels of envy compared to their male counterparts. It is noteworthy that some of the results are contradictory to findings of the previous studies. For instance, social interaction appeared as biggest reason for envy in Pakistani culture, which is not the case in the earlier studies. Hence, in the future, we intend to conduct similar studies in other developing countries to confirm the results.

\section{References}

[1] D. Evans, "Social media marketing: An hour a day." John Wiley \& Sons, 2008. Article (CrossRef Link)

[2] D. Zarrella, "The social media marketing book," O’Reilly Media, Inc., 2009. Article (CrossRef Link)

[3] E. C. Tandoc, P. Ferrucci, and M. Duffy, "Facebook use, envy, and depression among college students: Is facebooking depressing?,” Comput. Hum. Behav., vol. 43, pp. 139-146, 2015. Article (CrossRef Link)

[4] M. Tariq and F. Wahid, "Assessing effectiveness of social media and traditional marketing approaches in terms of cost and target segment coverage,” Interdiscip. J. Contemp. Res. Bus., vol. 3, no. 1, pp. 1049-1074, 2011. Article (CrossRef Link)

[5] C. Pring, “100 social media statistics for 2012,” Soc. Ski., vol. 11, 2012. Article (CrossRef Link)

[6] S. Valenzuela, N. Park, and K. F. Kee, "Is there social capital in a social network site?: Facebook use and college students' life satisfaction, trust, and participation,” J. Comput.-Mediat. Commun., vol. 14, no. 4, pp. 875-901, 2009. Article (CrossRef Link)

[7] P. S. Meena, P. K. Mittal, and R. K. Solanki, "Problematic use of social networking sites among urban school going teenagers," Ind. Psychiatry J., vol. 21, no. 2, p. 94, 2012. Article (CrossRef Link)

[8] F. Griffiths et al., "The impact of online social networks on health and health systems: a scoping review and case studies," Policy Internet, vol. 7, no. 4, pp. 473-496, 2015. Article (CrossRef Link)

[9] M. Hill, "Facebook Stirs Jealousy." Associated Press, 2009.

[10] J. L. Eby, “The Effects of Facebook on Jealousy in Relationships,” 2009. Article (CrossRef Link)

[11] M. Shojafar, Z. Pooranian, P. G. V. Naranjo, and E. Baccarelli, "FLAPS: bandwidth and delay-efficient distributed data searching in Fog-supported P2P content delivery networks,” $J$ Supercomput, vol. 73, no. 12, pp. 5239-5260, Dec. 2017. Article (CrossRef Link)

[12] P. G. V. Naranjo, Z. Pooranian, M. Shojafar, M. Conti, and R. Buyya, "FOCAN: A Fog-supported Smart City Network Architecture for Management of Applications in the Internet of Everything Environments," arXiv:1710.01801 [cs], Oct. 2017. Article (CrossRef Link)

[13] T. Haselton, "Facebook just admitted that using Facebook can be bad for you," CNBC, 15-Dec-2017. [Accessed: 16-Dec-2017]. Article (CrossRef Link) 
[14] J. M. Twenge and J. D. Foster, "Mapping the scale of the narcissism epidemic: Increases in narcissism 2002-2007 within ethnic groups,” J. Res. Personal., vol. 42, no. 6, pp. 1619-1622, 2008. Article (CrossRef Link)

[15] S. Malik and M. Khan, "Impact of facebook addiction on narcissistic behavior and self-esteem among students," J Pak Med Assoc, vol. 65, no. 3, pp. 260-263, 2015. Article (CrossRef Link)

[16] E. Ronningstam, "Narcissistic personality disorder: a current review," Curr. Psychiatry Rep., vol. 12, no. 1, pp. 68-75, 2010. Article (CrossRef Link)

[17] C. J. Carpenter, “Narcissism on Facebook: Self-promotional and anti-social behavior,” Personal. Individ. Differ., vol. 52, no. 4, pp. 482-486, 2012. Article (CrossRef Link)

[18] C. Yang and B. B. Brown, "Online self-presentation on Facebook and self development during the college transition,” J. Youth Adolesc., vol. 45, no. 2, pp. 402-416, 2016. Article (CrossRef Link)

[19] A. Muise, E. Christofides, and S. Desmarais, "More information than you ever wanted: Does Facebook bring out the green-eyed monster of jealousy?,” Cyberpsychol. Behav., vol. 12, no. 4, pp. 441-444, 2009. Article (CrossRef Link)

[20] S. E. Hill, D. J. DelPriore, and P. W. Vaughan, "The cognitive consequences of envy: attention, memory, and self-regulatory depletion.”’ J. Pers. Soc. Psychol., vol. 101, no. 4, p. 653, 2011. Article (CrossRef Link)

[21] G. M. Foster et al., "The anatomy of envy: A study in symbolic behavior [and comments and reply],” Curr. Anthropol., vol. 13, no. 2, pp. 165-202, 1972. Article (CrossRef Link)

[22] H. Krasnova, T. Widjaja, P. Buxmann, H. Wenninger, and I. Benbasat, "Research note-why following friends can hurt you: an exploratory investigation of the effects of envy on social networking sites among college-age users,” Inf. Syst. Res., vol. 26, no. 3, pp. 585-605, 2015. Article (CrossRef Link)

[23] PTA, “Annual Report 2016,” Pakistan Telecommunication Authority, 2016. Article (CrossRef Link)

[24] W. Desk, "Pakistan crosses 8 million Facebook users," The Express Tribune, 2012. Article (CrossRef Link)

[25] P. Singla and M. Richardson, "Yes, there is a correlation:-from social networks to personal behavior on the web," in Proc. of Proceedings of the 17th international conference on World Wide Web, 2008, pp. 655-664. Article (CrossRef Link)

[26] J. Leskovec and E. Horvitz, "Planetary-scale views on a large instant-messaging network," in Proc. of Proceedings of the 17th international conference on World Wide Web, 2008, pp. 915-924. Article (CrossRef Link)

[27] J. D. Underwood, L. Kerlin, and L. Farrington-Flint, “The lies we tell and what they say about us: Using behavioural characteristics to explain Facebook activity,” Comput. Hum. Behav., vol. 27, no. 5, pp. 1621-1626, 2011. Article (CrossRef Link)

[28] S. V. Halliday, "User-generated content about brands: Understanding its creators and consumers," J. Bus. Res., vol. 69, no. 1, pp. 137-144, 2016. Article (CrossRef Link)

[29] T. A. Pempek, Y. A. Yermolayeva, and S. L. Calvert, “College students' social networking experiences on Facebook,” J. Appl. Dev. Psychol., vol. 30, no. 3, pp. 227-238, 2009. Article (CrossRef Link)

[30] M. Kalpidou, D. Costin, and J. Morris, “The relationship between Facebook and the well-being of undergraduate college students,” CyberPsychology Behav. Soc. Netw., vol. 14, no. 4, pp. 183-189, 2011. Article (CrossRef Link)

[31] C. Steinfield, N. B. Ellison, and C. Lampe, "Social capital, self-esteem, and use of online social network sites: A longitudinal analysis,” J. Appl. Dev. Psychol., vol. 29, no. 6, pp. 434-445, 2008. Article (CrossRef Link)

[32] M. S. Bernstein, E. Bakshy, M. Burke, and B. Karrer, "Quantifying the invisible audience in social networks," in Proc. of Proceedings of the SIGCHI conference on human factors in computing systems, 2013, pp. 21-30. Article (CrossRef Link)

[33] J. Falender, "Bernadette H. Schell: Online Health and Safety: From Cyberbullying to Internet Addiction,” J. Youth Adolesc., vol. 2, no. 46, pp. 478-481, 2016. Article (CrossRef Link) 
[34] C. Smith-Duff, "Facebook use and its relationship with self-esteem, personalities and addictive tendencies," Dublin Business School, 2012. Article (CrossRef Link)

[35] H. Krasnova, H. Wenninger, T. Widjaja, P. Buxmann, and others, "Envy on Facebook: A Hidden Threat to Users' Life Satisfaction?,” in Proc. of Wirtschaftsinformatik 2013, 2013. Article (CrossRef Link)

[36] H.-T. G. Chou and N. Edge, “'They are happier and having better lives than I am': the impact of using Facebook on perceptions of others’ lives,” Cyberpsychology Behav. Soc. Netw., vol. 15, no. 2, pp. 117-121, 2012. Article (CrossRef Link)

[37] R. H. Smith and S. H. Kim, “Comprehending envy.,” Psychol. Bull., vol. 133, no. 1, p. 46, 2007. Article (CrossRef Link)

[38] K. Tai, J. Narayanan, and D. J. McAllister, "Envy as pain: Rethinking the nature of envy and its implications for employees and organizations,” Acad. Manage. Rev., vol. 37, no. 1, pp. 107-129, 2012. Article (CrossRef Link)

[39] Y. Cohen-Charash, “Episodic envy,” J. Appl. Soc. Psychol., vol. 39, no. 9, pp. 2128-2173, 2009. Article (CrossRef Link)

[40] D. D. Beer, "Social network(ing) sites.... revisiting the story so far: A response to danah boyd \& Nicole Ellison,” J. Comput.-Mediat. Commun., vol. 13, no. 2, pp. 516-529, 2008. Article (CrossRef Link)

[41] K. Subrahmanyam and P. Greenfield, "Online communication and adolescent relationships," Future Child., vol. 18, no. 1, pp. 119-146, 2008. Article (CrossRef Link)

[42] P. M. Valkenburg, J. Peter, and A. P. Schouten, "Friend networking sites and their relationship to adolescents’ well-being and social self-esteem,” Cyberpsychol. Behav., vol. 9, no. 5, pp. 584-590, 2006. Article (CrossRef Link)

[43] N. Haferkamp and N. C. Krämer, "Social comparison 2.0: Examining the effects of online profiles on social-networking sites,” Cyberpsychology Behav. Soc. Netw., vol. 14, no. 5, pp. 309-314, 2011. Article (CrossRef Link)

[44] E. A. Vogel, J. P. Rose, L. R. Roberts, and K. Eckles, "Social comparison, social media, and self-esteem.,” Psychol. Pop. Media Cult., vol. 3, no. 4, p. 206, 2014. Article (CrossRef Link)

[45] J. B. Walther, "Selective self-presentation in computer-mediated communication: Hyperpersonal dimensions of technology, language, and cognition,” Comput. Hum. Behav., vol. 23, no. 5, pp. 2538-2557, 2007. Article (CrossRef Link)

[46] A. H. Jordan, B. Monin, C. S. Dweck, B. J. Lovett, O. P. John, and J. J. Gross, "Misery has more company than people think: Underestimating the prevalence of others' negative emotions," Pers. Soc. Psychol. Bull., vol. 37, no. 1, pp. 120-135, 2011. Article (CrossRef Link)

[47] R. J. Lee-Won, M. Shim, Y. K. Joo, and S. G. Park, "Who puts the best 'face' forward on Facebook?: Positive self-presentation in online social networking and the role of self-consciousness, actual-to-total Friends ratio, and culture,” Comput. Hum. Behav., vol. 39, pp. 413-423, 2014. Article (CrossRef Link)

[48] H. Appel, A. L. Gerlach, and J. Crusius, "The interplay between Facebook use, social comparison, envy, and depression,” Curr. Opin. Psychol., vol. 9, pp. 44-49, 2016. Article (CrossRef Link)

[49] M. N. Saunders, A. Thornhill, P. Lewis, "Research methods for business students, 5/e. Pearson Education India, 2011. Article (CrossRef Link)

[50] J. W. Creswell, "Research design: Qualitative, quantitative, and mixed methods approaches," Sage publications, 2013. Article (CrossRef Link)

[51] U. Sekaran and R. Bougie, "Research methods for business: A skill building approach," John Wiley \& Sons, 2016. Article (CrossRef Link)

[52] J. W. Creswell and J. D. Creswell, "Research design: Qualitative, quantitative, and mixed methods approaches," Sage publications, 2017. Article (CrossRef Link)

[53] W. M. Kuzon Jr, M. G. Urbanchek, and S. McCabe, "The seven deadly sins of statistical analysis.,” Ann. Plast. Surg., vol. 37, no. 3, pp. 265-272, 1996. Article (CrossRef Link)

[54] E. Svensson and others, "Guidelines to statistical evaluation of data from rating scales and questionnaires,” J. Rehabil. Med., vol. 33, no. 1, pp. 47-48, 2001. Article (CrossRef Link) 
[55] E. Diener, R. Emmons, R. Larsen, and S. Griffin, “The satisfaction With Life Scale,” J. Pers. Assess., vol. 49, pp. 71-75, 1985. Article (CrossRef Link)

[56] N. K. Malhotra, "Marketing research: An applied orientation, 5/e," Pearson Education India, 2008. Article (CrossRef Link)
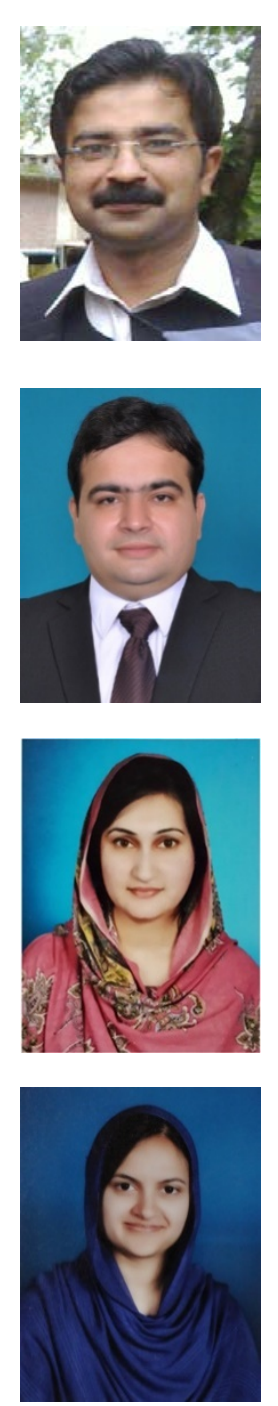

Dr. Tassawar Iqbal is presently serving as Assistant Professor at Department of Computer Science in COMSATS Institute of Information Technology, Wah, Pakistan. He completed his PhD degree from Vienna University of Technology in 2012. His current research interests include: 1) Computer Assisted Solutions for Adult Basic Education (ABE), 2) Designing learning content for $\mathrm{ABE}$, 3) Impact of Computer Assisted Solutions (CAS) on ABE learners 4) Learning Styles and Multiple Intelligences in CAS, 5) Adaptive CAS, and 6) Social Networks and Societies. He has 12 publications in above mentioned areas of interests, published in reputed journals and conferences.

Muhammad Tariq Yousafzai is currently working as Assistant Professor at FAST-National University of Computer \& Emerging Sciences, with over 10 years teaching and research experience. He is a PhD Candidate at Qurtuba University of Science \& Information technology, Peshawar and holds MS in Innovation and Business Creation degree from Jonkoping International Business School (JIBS), Sweden.

Sabeen Ali received her Bachelor degree in Telecommunication and Networking from COMSATS Institute of Information Technology, Abbottabad in 2012. She obtained her Master degree in Computer Science from the same university in 2014. Her research interests include issues related with social networks, NoC-based MPSoC systems, and run-time mapping algorithms. She has coauthored in "Dynamic task mapping for Network-on-Chip based systems".

Kinza Sattar joined University of Gujrat Sialkot sub-campus, Pakistan as a lecturer in 2015. Currently she is serving at The University of Lahore, Islamabad, Pakistan. She received her BS in Telecommunication and Networking (2012) and MS in Computer Science (2015) from COMSATS Abbottabad, Pakistan. Her current research interest is in efficient utilization of infrastructure in smart cities. 

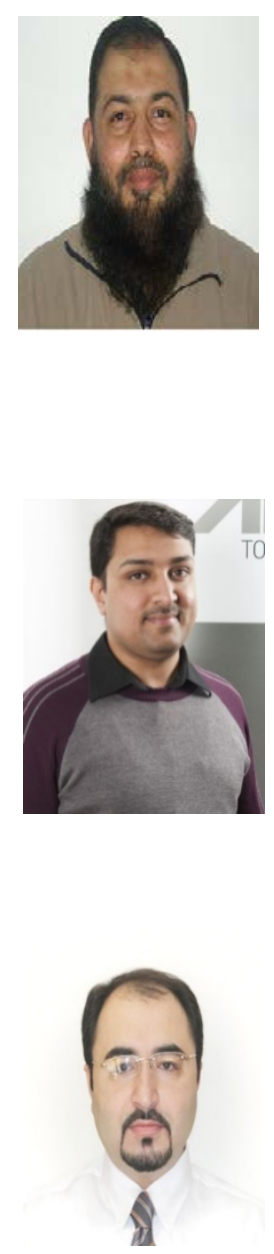

Dr. Muhammad Qaiser Saleem is currently a working as Assistant Professor in Collage of Computer Science and Information Technology, Al Baha University, Al Baha, Saudi Arabia Since August 2013. He has completed his PhD. in Information Technology from Universiti Teknologi PETRONAS (UTP), Malaysia in 2013. He has completed his MS in Computer Sciences from Malardalen University, Vasteras, Sweden in 2006. He has obtained his first Mater in Computer Sciences from International Islamic University, Islamabad, Pakistan, in 1998. During his professional career he remained involved in academia as well as IT industry and being involved in various development projects related to Databases and Data Warehousing environment. He is also involved in various research projects. Currently his main research interest is Modelling of Security Requirement during Business Process Modelling in SOA Application.

Dr. Usman Habib is currently serving as Assistant Professor \& Coordinator graduate program committee at the department of computer science, FAST National University of Computers \& Emerging Sciences. He holds more than ten years of teaching and research experience spanning from 2006 to date. Along with teaching and research, he has also worked and successfully completed different industrial projects. He has completed his PhD at ICT department, Technical university of Vienna, Austria and obtained his Master's degree from the Norwegian University of Science and Technology, (NTNU), Norway in the year 2008. Dr. Usman has been actively involved in research as well, and has authored several conference and journal publications. He is currently interested in the fields of machine learning, data analytics, solar cooling systems and fault detection and diagnosis systems.

Dr. Atta Ur Rehman Khan is the Head of AU Cybersecurity Center and Associate Professor at Department of Computer Science, Air University. He is an Associate Editor of IEEE Access, Elsevier Journal of Network and Computer Applications, Associate Technical Editor of IEEE Communications Magazine, Editor of Springer Journal of Cluster Computing, Oxford Computer Journal, IEEE SDN Newsletter, KSII Transactions on Internet and Information Systems, SpringerOpen Human-centric Computing and Information Sciences, SpringerPlus, and Ad hoc \& Sensor Wireless Networks journal. Moreover, he is a Senior Member of IEEE and professional member of ACM. He is a member of Cloud Security Alliance (CSA) Pakistan, and Steering Committee Member/ PC Chair/ Track Chair/ Technical Program Committee (TPC) member of over 60 international conferences. His areas of research interest include cybersecurity, mobile cloud computing, ad hoc networks, and IoT. 